\title{
Evaluation of the effect of glutathione on cisplatin antitumor activity and kidney injury at different administration times
}

\author{
YAN-YAN XU ${ }^{1}$, NA JIANG ${ }^{2}$, TONG-SHEN LIU ${ }^{3}$, HUI-QING QU $^{4}$ and TIAN WANG ${ }^{5}$ \\ ${ }^{1}$ Department of Cell Biology, Binzhou Medical University, Yantai, Shandong; ${ }^{2}$ Department of Pharmacy, \\ Dalian Sixth People's Hospital, Dalian, Liaoning; ${ }^{3}$ Department of Histology and Embryology, Binzhou Medical University, \\ Yantai; ${ }^{4}$ Department of Transfusion, The Affiliated Hospital of Binzhou Medical University, Binzhou, Shandong; \\ ${ }^{5}$ Department of Pharmacology, School of Pharmacy, Yantai University, Yantai, Shandong, P.R. China
}

Received February 28, 2012; Accepted July 16, 2012

DOI: $10.3892 / \mathrm{mmr} .2012 .1033$

\begin{abstract}
Cisplatin (cis-diamminedichloroplatinum, CDDP) is one of the most potent anticancer drugs. However, the therapeutic value of CDDP is greatly compromised by its dose-limiting nephrotoxicity. This study was performed to investigate whether reduced glutathione (GSH) was able to reduce the kidney injury induced by CDDP and whether it affected the anticancer activity of CDDP in vivo and in vitro. In in vivo experiments, mice were divided into five groups: control, CDDP only and three GSH treatment groups. Blood samples were collected $72 \mathrm{~h}$ after CDDP administration to determine the levels of blood urea nitrogen (BUN) and plasma creatinine $(\mathrm{Cr})$. In addition, we examined antioxidative parameters, malondialdehyde (MDA) levels and histopathological changes in the kidney. In order to investigate whether GSH affected the anticancer activity of CDDP, we performed a sulforhodamine B (SRB) assay to determine the antiproliferative effect in three tumor cell lines of treatment with CDDP alone or combined with GSH and examined the cell morphology. The results revealed that GSH decreased the BUN and Cr levels in plasma, ameliorated the pathological changes induced by CDDP and enhanced the endogenous antioxidant capacities in all three GSH groups. Furthermore, GSH significantly inhibited the growth of the three tumor cell lines when combined with CDDP and did not affect the inhibitory effect of CDDP on the carcinoma cell proliferation. In addition, we found no differences among the three GSH groups. These findings suggest that GSH is able to attenuate the nephrotoxicity induced by CDDP, not only when administered prior to CDDP, but also when administered at the same time as or subsequent to CDDP administration, without affecting the
\end{abstract}

Correspondence to: Ms. Na Jiang, Department of Pharmacy, Dalian Sixth People's Hospital, 169 Huibai Road, Dalian, Liaoning 116114, P.R. China

E-mail: bzmcxyy@yahoo.cn

Key words: reduced glutathione, cisplatin, cytotoxicity, kidney toxicity, different administration times anticancer activity of CDDP. Thus, the administration of GSH is a promising approach for attenuating the nephrotoxicity caused by CDDP.

\section{Introduction}

Cisplatin (cis-diamminedichloroplatinum, CDDP) is a chemotherapeutic drug used to treat various types of cancer, including sarcomas, certain carcinomas, such as small cell lung and ovarian cancers, lymphomas, and germ cell tumors (1). CDDP reacts in vivo, binding to and causing crosslinking of DNA, which ultimately triggers apoptosis/programmed cell death (2). Despite its desirable anticancer therapeutic value, CDDP-based chemotherapy has a number of dose-limiting side-effects, the most severe being nephrotoxicity $(3,4)$. The glomerular filtration rate may decrease by $30 \%$ after only two doses, often making the continuation of the treatment implausible (5). The CDDP-induced alterations in kidney function are characterized by signs of injury, including changes in glutathione (GSH) status and lipid peroxidation (LPO) levels (6). Therefore, the investigation of reagents that can reduce the nephrotoxicity of CDDP without affecting its anticancer effectiveness is critical for the successful administration of the drug and the survival rates of cancer patients.

GSH has been shown to be an effective protector against CDDP-induced nephrotoxicity in various rodent models. Zunino et al (7) found that GSH had a protective effect against CDDP-induced renal toxicity only when administered prior to CDDP and the mechanisms of the protective effect were not clear. The present study expands previous observations by investigating the protective effect of GSH against CDDP-induced renal toxicity when administered at various times and exploring its mechanisms of action. Additionally, whether GSH affected the antitumor effect of CDDP in the three tumor cell lines was also investigated. Oxidative stress has been reported in CDDP-induced nephrotoxicity. Kidneys contain antioxidant enzymes, including superoxide dismutase (SOD), lipid peroxides and GSH, which protect the kidney from free radicals and superoxides. Subsequent to CDDP administration, GSH levels as well as the activities of SOD and GSH-peroxidase (GSH-Px) are decreased (8). GSH is a tripeptide compound containing a sulfhydryl (thiol) group. As with 
all thiol group-containing molecules, GSH is an antioxidant, preventing the damage to important cellular components caused by reactive oxygen species, including free radicals and peroxides (9). GSH has no known toxicity. Clinically, it is used as a supplementary antineoplastic drug, but its half-life when administered intravenously (i.v.) is only $15 \mathrm{~min}$. Thus, to avoid GSH decreasing the effect of anticancer drugs, it is most commonly administered prior to CDDP and is administered continuously for 15-20 min. To the best of our knowledge, the best method of administering GSH, the existence of any differences between the effects of the different GSH administration methods and whether GSH is able to protect against the kidney injury induced by CDDP, have not been reported. The aim of this study was to investigate whether reduced GSH is capable of reducing the kidney injury induced by CDDP and whether it affects the anticancer activity of CDDP in vivo and in vitro.

\section{Materials and methods}

Chemicals and instruments. CDDP was obtained from Qilu Pharmaceutical Co., Ltd. (Shandong, China). GSH was supplied by Shandong Luye Pharmaceutical Co., Ltd. (Yantai, China). RPMI-1640 cell culture medium was purchased from Gibco-BRL (Grand Island, NY, USA). Sulforhodamine B (SRB) was purchased from Sigma (St. Louis, MO, USA). Fetal bovine serum was purchased from Hangzhou Sijiqing Biological Engineering Materials Co., Ltd. (Hangzhou, China). Blood urea nitrogen (BUN), creatinine (Cr), SOD, GSH-Px and malondialdehyde (MDA) test kits were purchased from the Jiancheng Bioengineering Institute (Nanjing, China). Any other chemicals and reagents used in this study were of analytical grade. GSH was diluted with normal saline. The TDL-40B refrigerated centrifuge was obtained from the Shanghai Anting Scientific Instrument Factory (Shanghai, China). The Synergy HT Microplate Reader was from BioTek Instruments, Inc. (Winooski, VT, USA). The FJ-200S highspeed tissue homogenate machine was from the Shanghai Specimen and Model Factory (Shanghai, China).

Animals and drug treatment. Adult female Swiss mice weighing 22-28 g were obtained from the Experimental Animal Center of Shandong Province (Certificate no. 20041225). All experimental procedures carried out in this study were performed in accordance with the guidelines for the care and use of laboratory animals of Yantai University and were approved by the Ethics Committee. The mice were kept with free access to food and water on a 12-h light/dark cycle. The animals were housed in plastic cages and randomly assigned to 5 groups as follows: control, CDDP-intoxicated $(20 \mathrm{mg} / \mathrm{kg}$ i.v.), GSH-treated 1 (pretreated with GSH at doses of $1,200 \mathrm{mg} / \mathrm{kg}$ i.v. for three consecutive days), GSH-treated 2 (treated with GSH at doses of $1,200 \mathrm{mg} / \mathrm{kg}$ i.v. $30 \mathrm{~min}$ subsequent to CDDP intoxication) and GSH-treated 3 (treated with GSH at doses of $1,200 \mathrm{mg} / \mathrm{kg}$ i.v. for three consecutive days subsequent to CDDP intoxication). Each group contained 10 animals and the animals in the control group were injected with normal saline in equivalent volumes. Seventy-two hours after a single injection of CDDP, the acute kidney injury model was established, the mice were sacrificed and blood samples were collected from the orbital venous plexus for determination of plasma BUN and Cr levels. Kidneys were removed for the determination of SOD and GSH-Px activities, MDA levels and for histological examination.

Histopathology. Paraformaldehyde (4\%)-fixed and paraffin-embedded kidney samples were cut into $4-\mu \mathrm{m}$ sections, deparaffinized in xylene and rehydrated through a series of decreasing concentrations of ethanol. Sections were stained with hematoxylin and eosin. Pathological observation of the tissue was performed by light microscopy.

Biochemical analysis. On the day of the sacrifice, blood was collected immediately and blood samples were drawn into heparinized tubes for biochemical analysis. The samples were centrifuged immediately ( $3500 \mathrm{xg}$ for $10 \mathrm{~min}$ at $4^{\circ} \mathrm{C}$ ), and the plasma was stored at $-80^{\circ} \mathrm{C}$.

The kidney was homogenized in ice-cold normal saline $(1 / 9, \mathrm{w} / \mathrm{v})$ at a speed of $5000 \mathrm{rpm}(5 \times 15 \mathrm{sec}$, in the ice water bath). The suspension was centrifuged at a speed of $2000 \mathrm{rpm}$ for $10 \mathrm{~min}$ at $4^{\circ} \mathrm{C}$ and the supernatant was stored at $-80^{\circ} \mathrm{C}$.

The BUN and Cr levels of the plasma and the SOD and GSH-Px activities and MDA levels in the kidney homogenate supernatants were determined according to the instructions of the respective test kits. Antioxidant enzyme activities and MDA levels were expressed as U/mg protein and were determined by the Coomassie Blue method.

Cell lines. The lung (A549) and gastric (SGC-7901) carcinoma cell lines, as well as the breast cancer cell line (MCF-7) were obtained from the School of Pharmacy, Yantai University. The tumor cells were routinely maintained in RPMI-1640 medium supplemented with $10 \%$ fetal bovine serum, $100 \mathrm{U} / \mathrm{ml}$ penicillin and $100 \mu \mathrm{g} / \mathrm{ml}$ streptomycin. The cells were cultured at $37^{\circ} \mathrm{C}$, under an atmosphere containing $5 \% \mathrm{CO}_{2}$ at $95 \%$ relative humidity.

Cytotoxicity assays. Cytotoxicity was evaluated by an SRB assay using 96-well plates (10). In the SRB assay, the cell suspension $(100 \mu \mathrm{l})$ was plated at a density of $5 \times 10^{4}$ cells $/ \mathrm{ml}$ and incubated for $24 \mathrm{~h}$. The medium was removed and replaced with drugs. The plates were then allowed to incubate for up to $48 \mathrm{~h}$ and the cells were fixed with $50 \%$ (w/v) trichloroacetic acid (TCA) for $1 \mathrm{~h}$ at $4^{\circ} \mathrm{C}$. After washing with distilled $\mathrm{H}_{2} \mathrm{O}$ to remove TCA, the cell layer was stained with $0.4 \%(\mathrm{w} / \mathrm{v})$ SRB in $1 \%$ acetic acid for $30 \mathrm{~min}$. After extensive washing with $1 \%(\mathrm{v} / \mathrm{v})$ acetic acid, the protein-bound dye was dissolved in $10 \mathrm{mM}$ Tris base solution and the optical density was determined at $515 \mathrm{~nm}$. Duplicate plates containing the single agent, the combination and the control groups were subjected to the SRB assay. The inhibition rate (\%) was calculated as $\left(\mathrm{A}_{\text {control }}-\mathrm{A}_{\text {sample }}\right) / \mathrm{A}_{\text {control }} \times 100 \%$, where $\mathrm{A}_{\text {control }}$ is the control absorbance and $\mathrm{A}_{\text {sample }}$ is the test sample absorbance. The groups and administration quantities used to treat the three tumor cell lines are shown in Table I.

Cell morphology. The A549, SGC-7901 and MCF-7 cells were exposed to fresh medium, CDDP, GSH and CDDP combined with GSH for $24 \mathrm{~h}$ as described in the cytotoxicity assays. The cell morphology changes of each group were observed using an inverted microscope. 
Table I. Groups and administration in cytotoxicity assays.

\begin{tabular}{lcccc}
\hline Group & $\begin{array}{c}\text { Fresh } \\
\text { medium } \\
(\mu \mathrm{l})\end{array}$ & $\begin{array}{c}\text { GSH } \\
60 \mu \mathrm{g} / \mathrm{ml} \\
(\mu \mathrm{l})\end{array}$ & $\begin{array}{c}\text { GSH } \\
120 \mu \mathrm{g} / \mathrm{ml} \\
(\mu \mathrm{l})\end{array}$ & $\begin{array}{c}\text { CDDP } \\
6 \mu \mathrm{g} / \mathrm{ml} \\
(\mu \mathrm{l})\end{array}$ \\
\hline Control & 200 & - & - & - \\
$\mathrm{GSH}(30 \mu \mathrm{g} / \mathrm{ml})$ & 100 & 100 & - & - \\
$\mathrm{GSH}(60 \mu \mathrm{g} / \mathrm{ml})$ & 100 & - & 100 & - \\
$\mathrm{CDDP}(3 \mu \mathrm{g} / \mathrm{ml})$ & 100 & - & - & 100 \\
$\mathrm{GSH}+\mathrm{CDDP}$ & - & 100 & - & 100 \\
$(30+3 \mu \mathrm{g} / \mathrm{ml})$ & & & & 100 \\
$\mathrm{GSH}+\mathrm{CDDP}$ & - & - & 100 & \\
$(60+3 \mu \mathrm{g} / \mathrm{ml})$ & & & &
\end{tabular}

GSH, glutathione; CDDP, cisplatin.

Acridine orangelethidium bromide (AO/EB) fluorescence staining. Cellular morphological changes were investigated by AO/EB staining using fluorescence microscopy. The A549 cells were exposed to fresh medium, CDDP, GSH and CDDP combined with GSH for $24 \mathrm{~h}$. Cells from the various groups were collected and prepared into single-cell suspensions and the cell concentration was adjusted to $1 \times 10^{7} / \mathrm{ml}$ with PBS buffer. Adhesive and suspended cells were collected, pooled, pelleted and resuspended in $200 \mu \mathrm{l}$ medium. An 8- $\mu \mathrm{l}$ mixture of fluorescent dyes containing $100 \mu \mathrm{g} / \mathrm{ml} \mathrm{AO}$ and $100 \mu \mathrm{g} / \mathrm{ml}$ EB (Sigma) was then added to the cells and mixed gently. A drop of the mixture was placed on a microscope slide and covered with a coverslip. The cells were visualized under a fluorescent microscope (x100) (Nikon, Tokyo, Japan), using a blue filter.

Statistical analysis. One-way ANOVA was used to analyze the significant differences among the various groups. Comparisons between the two groups were determined by the Student's unpaired t-test, using SPSS 11.5 statistical software. $\mathrm{P}<0.05$ was considered to indicate a statistically significant result. The renal cortical slices for each experiment were from at least three mice. Data in this study were expressed as the mean \pm SD.

\section{Results}

Effect of GSH on the histopathologic changes in the kidney induced by $C D D P$. In the control group, the renal cortical sections were normal (Fig. 1a). CDDP treatment resulted in necrosis of the proximal tubules at various foci throughout the cortex, karyomegaly, hyaline casts in tubular lumen, desquamation and parenchymal degeneration of the tubular epithelium cells (Fig. 1b). Treatment with GSH (1,200 mg/kg) at various times significantly improved the CDDP-induced renal tubular necrosis and degenerative changes (Fig. 1c-e).

Effect of GSH on the plasma BUN and Cr levels in mice treated with CDDP. The levels of BUN and $\mathrm{Cr}$ were measured $72 \mathrm{~h}$ after the administration of CDDP. As shown in Fig. 2A and B, CDDP administration induced severe renal dysfunction, which was clearly attenuated by GSH and no

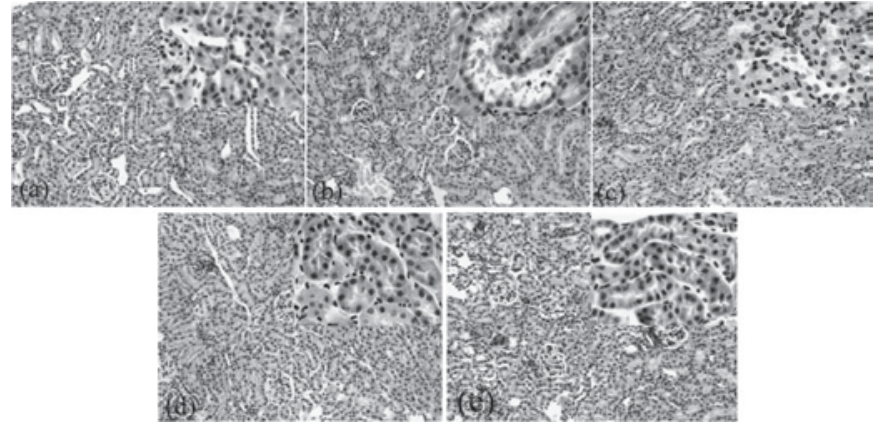

Figure 1. Effect of glutathione (GSH) on histopathologic changes in kidney induced by cisplatin (CDDP). (a) Control, (b) CDDP, (c) GSH1, (d) GSH2 and (e) GSH3 groups

A

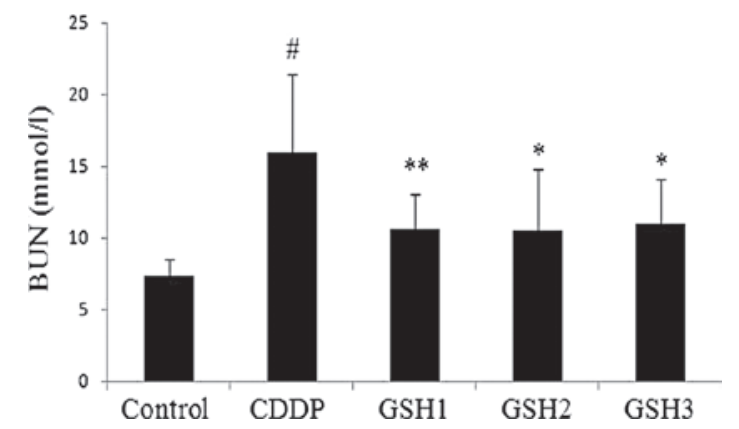

B

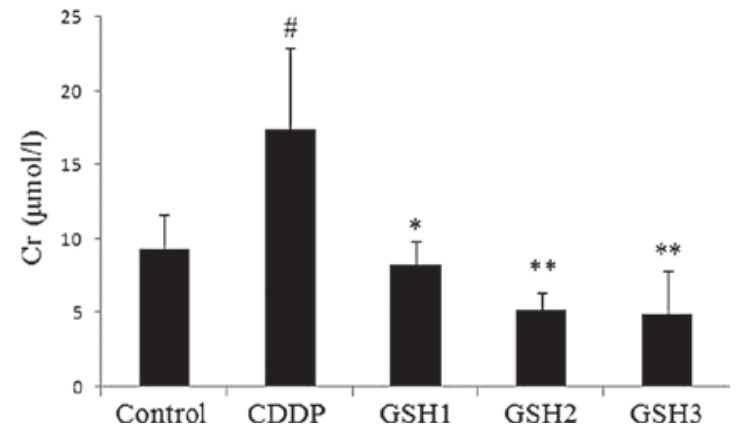

Figure 2. Effect of glutathione (GSH) on plasma (A) blood urea nitrogen $(\mathrm{BUN})$ and $(\mathrm{B})$ creatinine $(\mathrm{Cr})$ contents in CDPP-intoxicated mice $(\mathrm{n}=8)$. ${ }^{\#} \mathrm{P}<0.01$ compared with the control group; ${ }^{* *} \mathrm{p}<0.01,{ }^{*} \mathrm{p}<0.05$, compared with the cisplatin (CDDP)-treated group.

differences were observed among the three GSH groups. The BUN and $\mathrm{Cr}$ levels in the control mice prior to the injection of CDDP were $7.34 \mathrm{mmol} / 1$ and $9.40 \mu \mathrm{mol} / 1$, respectively. The injection of CDDP $(20 \mathrm{mg} / \mathrm{kg})$ produced an elevation of the BUN and $\mathrm{Cr}$ levels ( $\mathrm{p}<0.01)$. The GSH-treated groups had markedly decreased BUN and $\mathrm{Cr}$ levels $72 \mathrm{~h}$ after CDDP administration $(\mathrm{p}<0.01, \mathrm{p}<0.05)$.

Effect of GSH on the SOD and GSH-Px activities and MDA levels in the kidney subsequent to CDDP administration. The activity of SOD in the kidney was significantly decreased $72 \mathrm{~h}$ after CDDP administration $(\mathrm{p}<0.01)$. The GSH treatment $(1,200 \mathrm{mg} / \mathrm{kg})$ increased the SOD activity $72 \mathrm{~h}$ later $(\mathrm{p}<0.01$, $\mathrm{p}<0.05$ ) (Fig. 3A). The activity of GSH-Px in the kidney was also decreased $72 \mathrm{~h}$ after CDDP administration ( $<<0.01)$. In addition, the GSH treatment $(1,200 \mathrm{mg} / \mathrm{kg})$ increased GSH-Px activity significantly $72 \mathrm{~h}$ later $(\mathrm{p}<0.01, \mathrm{p}<0.05)$ (Fig. 3B). The MDA levels in the kidney were significantly increased $72 \mathrm{~h}$ 

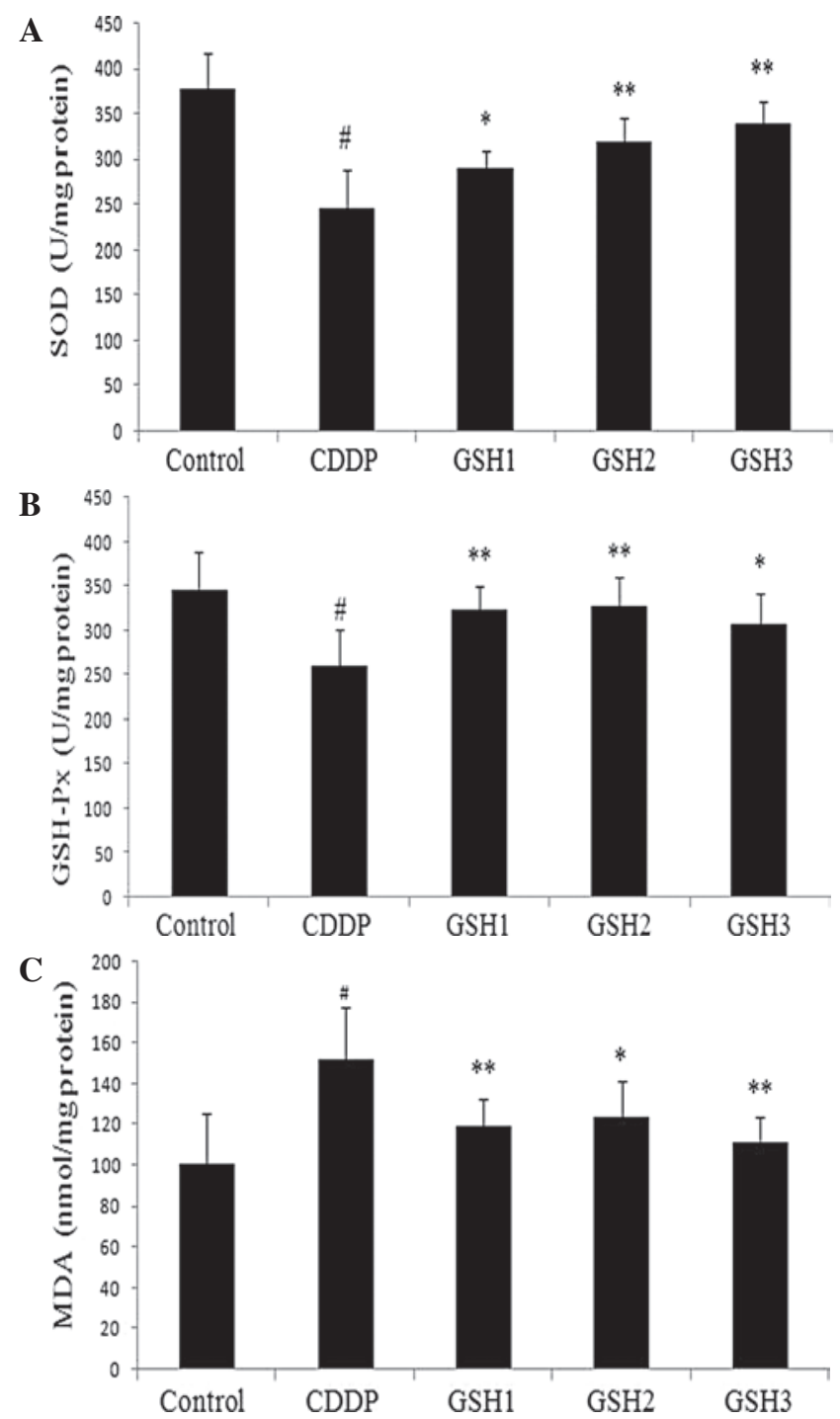

Figure 3. Effect of glutathione (GSH) on (A) superoxide dismutase (SOD) and (B) GSH-peroxidase (GSH-Px) activities and (C) malondialdehyde (MDA) levels in kidney following cisplatin (CDDP)-intoxication $(\mathrm{n}=8)$. ${ }^{\#} \mathrm{P}<0.01$ compared with the control group; ${ }^{* *} \mathrm{p}<0.01,{ }^{*} \mathrm{p}<0.05$ compared with the CDDP-treated group.

after CDDP administration $(\mathrm{p}<0.01)$. The GSH treatment $(1,200 \mathrm{mg} / \mathrm{kg})$ decreased the MDA levels $72 \mathrm{~h}$ later $(\mathrm{p}<0.01$, $\mathrm{p}<0.05$ ) (Fig. 3C).

The antiproliferative effects of CDDP alone or combined with GSH on cancer cells. The SRB assays demonstrated that CDDP combined with GSH significantly inhibited the proliferation of A549, SGC-7901 and MCF-7 cells. No significant differences were observed between the antiproliferative rates in the cancer cells of the GSH groups and the respective controls $(p>0.05)$ or between the low and high GSH concentration groups $(\mathrm{p}>0.05)$. The CDDP group was not observed to have any significant differences from the CDDP and GSH combination groups ( $\mathrm{p}>0.05)$ (Table II).

Morphological observation of tumor cells. Morphological observation was carried out using an inverted microscope. The results revealed the profiles of three tumor cell lines in the GSH and control groups to be clear with the cells growing

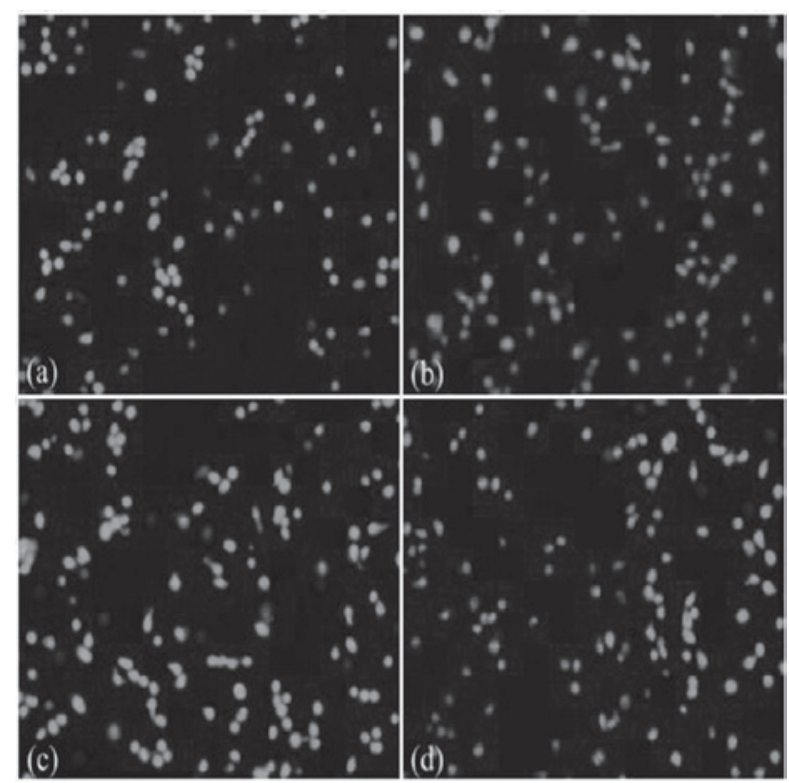

Figure 4. Observation using orange/ethidium bromide (AO/EB) fluorescence staining. (a) Control, (b) glutathione (GSH), (c) cisplatin (CDDP) and (d) CDDP + GSH groups. Cells in the control group received fresh medium (200 $\mu 1$ ). The GSH group received $100 \mu 1$ fresh medium and $100 \mu 1$ fresh medium containing GSH $(60 \mu \mathrm{g} / \mathrm{ml})$. The CDDP group received $100 \mu \mathrm{l}$ fresh medium and $100 \mu \mathrm{l}$ fresh medium containing CDDP $(6 \mu \mathrm{g} / \mathrm{ml})$. The CDDP $+\mathrm{GSH}$ group received fresh medium containing $100 \mu \mathrm{l} \mathrm{GSH}(60 \mu \mathrm{g} / \mathrm{ml})$ and $100 \mu \mathrm{l}$ CDDP $(6 \mu \mathrm{g} / \mathrm{ml})$

adherently in a polygonal shape. Subsequent to 24-h singleand combined-drug treatments, the cell density in the CDDP treatment and combination treatment groups decreased significantly and the volume of the cytoplasmic vesicles appeared larger than in the control and GSH groups. Apoptotic bodies and cell morphology changes were evident. Cells decreased in size and became rounded and smaller. The adherence capacity declined, while most cells dropped off and were floating. No significant differences were observed among the CDDP and the combination groups.

Detection of apoptosis using AO/EB fluorescence staining. AO is a cell-permeable dye that intercalates into DNA, resulting in a color change. EB enters cells with disrupted membranes and intercalates into RNA and double-stranded DNA. Thus, the differential uptake and binding of these dyes allowed us to identify cells in the early and late stages of apoptosis and necrosis.

In the CDDP and combination groups, when viewed under a fluorescent microscope, early apoptotic cells showed the presence of patches of fragmented and condensed chromatin and late apoptotic cells showed the presence of patches of fragmented and condensed chromatin (Fig. 4). No significant differences were observed among the CDDP and combination groups.

\section{Discussion}

CDDP is one of the most potent antitumor agents against a diverse spectrum of malignancies. However, the use of this agent in combating cancer is limited by its nephrotoxicity since it preferentially accumulates in human kidney cells (11). The 
Table II. Antiproliferative effects of CDDP alone or with GSH on cancer cells.

\begin{tabular}{|c|c|c|c|c|c|c|c|c|c|}
\hline \multirow[b]{2}{*}{ Group } & \multicolumn{3}{|c|}{ A549 } & \multicolumn{3}{|c|}{ SGC-7901 } & \multicolumn{3}{|c|}{ MCF-7 } \\
\hline & $\bar{\chi} \pm \mathrm{SD}$ & F & p-value & $\bar{\chi} \pm \mathrm{SD}$ & F & $\mathrm{p}$-value & $\bar{\chi} \pm \mathrm{SD}$ & $\mathrm{F}$ & p-value \\
\hline $\mathrm{GSH}(30 \mu \mathrm{g} / \mathrm{ml})$ & $2.363 \pm 0.084$ & & & $0.796 \pm 0.095$ & & & $1.823 \pm 0.068$ & & \\
\hline $\mathrm{GSH}(60 \mu \mathrm{g} / \mathrm{ml})$ & $2.395 \pm 0.134$ & 1.109 & $>0.05$ & $0.722 \pm 0.134$ & 0.490 & $>0.05$ & $1.798 \pm 0.106$ & 1.374 & $>0.05$ \\
\hline Control group & $2.312 \pm 0.054$ & & & $0.751 \pm 0.082$ & & & $1.885 \pm 0.041$ & & \\
\hline $\begin{array}{l}\text { GSH }(30 \mu \mathrm{g} / \mathrm{ml}) \\
+ \text { CDDP }\end{array}$ & $0.377 \pm 0.032$ & & & $0.148 \pm 0.013$ & & & $0.692 \pm 0.020$ & & \\
\hline $\begin{array}{l}\mathrm{GSH}(60 \mu \mathrm{g} / \mathrm{ml}) \\
+ \text { CDDP }\end{array}$ & $0.398 \pm 0.043$ & 2.003 & $>0.05$ & $0.133 \pm 0.009$ & 1.036 & $>0.05$ & $0.699 \pm 0.017$ & 0.947 & $>0.05$ \\
\hline CDDP & $0.333 \pm 0.084$ & & & $0.152 \pm 0.031$ & & & $0.710 \pm 0.021$ & & \\
\hline
\end{tabular}

Values are given as the mean $\pm \mathrm{SD}$. Cells in the control group received $200 \mu \mathrm{l}$ fresh medium. GSH 30 and $60 \mu \mathrm{g} / \mathrm{ml}$ groups received $100 \mu 1$ fresh medium and $100 \mu 1$ fresh medium containing GSH 60 and $120 \mu \mathrm{g} / \mathrm{ml}$, respectively. CDDP group received $100 \mu 1$ fresh medium and $100 \mu 1$ fresh medium containing CDDP $(6 \mu \mathrm{g} / \mathrm{ml})$. GSH $(30 \mu \mathrm{g} / \mathrm{ml})+$ CDDP and GSH $(60 \mu \mathrm{g} / \mathrm{ml})+$ CDDP groups received $100 \mu \mathrm{l}$ fresh medium containing GSH $(60 \mu \mathrm{g} / \mathrm{ml})$ and $100 \mu \mathrm{l} \mathrm{CDDP}(6 \mu \mathrm{g} / \mathrm{ml})$ or $100 \mu \mathrm{l} \mathrm{GSH}(120 \mu \mathrm{g} / \mathrm{ml})$ and $100 \mu \mathrm{l} \mathrm{CDDP}(6 \mu \mathrm{g} / \mathrm{ml})$, respectively. P $>0.05 \mathrm{indicates}$ no significant differences among the groups. GSH, glutathione; CDDP, cisplatin.

primary target of CDDP in the kidney is the S3 subsegments of the proximal tubular epithelial cells (12), where CDDP accumulates and causes cellular damage (13). CDDP-induced nephrotoxicity is associated with increased renal vascular resistance and morphological damage to the intracellular organelles, including cellular necrosis, loss of microvilli, changes in the number and size of lysosomes and mitochondrial vacuolization (14). There is a continuous search for agents that provide nephroprotection against CDDP and other platinum drugs, including antioxidants, modulators of nitric oxide, diuretics and cytoprotective and apoptotic agents (15). However, none of these agents have been found to be suitable for clinical use in the protection against CDDP-induced nephrotoxicity.

GSH is a vital nutrient for normal human cells. Currently, GSH is administered as a supplementary antineoplastic drug to mitigate the damage caused by chemotherapy. However, whether GSH acts as a nutrient to cancer cells or affects the anticancer activity of CDDP is not clear. Furthermore, in clinical use, GSH is usually administered prior to CDDP in order to avoid a nutritional effect on the tumor cells. Whether GSH may protect the kidney from injury, when administered following or at the time of CDDP administration, and its mechanism, are not clear. In this study, we demonstrated that the antioxidant GSH was able to attenuate the nephrotoxicity induced by CDDP, not only when administered prior to CDDP, but also when administered following or at the time of CDDP administration. In addition, GSH did not affect the anticancer activity of CDDP.

In vivo, we found that exogenously administered GSH effectively reduced nephrotoxicity in the mice treated with CDDP, as supported by the following evidence. Firstly, GSH improved the kidney's function in the clearance of BUN and $\mathrm{Cr}$ in the CDDP-treated mice. Secondly, GSH decreased the renal production of MDA in the CDDP-treated mice. Thirdly, GSH restored SOD and GSH-Px activities in the CDDPtreated mice. Therefore, the data suggest that GSH is effective in counteracting the nephrotoxic side effects of CDDP, while the three administration methods were observed to have no significant differences from each other.

However, a major concern remains with regard to whether GSH is likely to be a nutrient to tumor cells and affect the efficacy of CDDP in the treatment of cancer. Using the SRB assay, we showed that CDDP, whether administered alone, or combined with GSH of different concentrations, inhibited A549, SGC-7901 and MCF-7 tumor cell line proliferation to a similar extent, indicating that, at the concentrations tested, GSH has no significant effect on the cytotoxicity of CDDP towards tumor cells. GSH combined with CDDP may significantly arrest A549 cells in the G0/G1 phase and induce apoptosis to a certain extent (16). Under a fluorescent microscope, in the CDDP and the combination groups, early apoptotic cells showed the presence of green patches of fragmented and condensed chromatin and late apoptotic cells showed the presence of orange patches of fragmented and condensed chromatin. In comparison, viable cells were uniformly green and necrotic cells were uniformly orange (Fig. 4). The CDDP and combination groups were not observed to have any significant differences. This result is rather noteworthy, revealing that GSH differentially protects the normal cells from cytotoxicity but not the tumors.

CDDP therapy induces oxidative stress, largely involving ROS, including superoxide anions, hydrogen peroxide and hydroxyl radicals (17) in renal tubular cells (18). The decrease in antioxidant enzymes, including GSH-Px and SOD, further deteriorates the situation by allowing more ROS to accumulate. The interaction of ROS with various cellular components may cause damage to DNA, proteins and lipids. The excessive ROS accumulation caused by CDDP may overwhelm the natural antioxidant defenses of the kidney cells and lead to LPO and delayed-onset kidney injury (19).

GSH reduces $\mathrm{H}_{2} \mathrm{O}_{2}$ and $\mathrm{LPO}$, and these reductions are catalyzed by GSH-Px (11). The early depletion of GSH following CDDP treatment appears to be necessary for the CDDP-induced LPO and subsequent toxicity. The decreased 
SOD activity may also cause the initiation and propagation of LPO in the CDDP-treated mice. The MDA concentration increases as a result of LPO. In our study, the GSH supplementary treatment consistently reversed the decrease in SOD and GSH-Px activities and the increase in MDA levels in the CDDP-treated mice, suggesting that the nephroprotective effect of GSH is partially mediated by the prevention of the CDDP-induced decline of renal antioxidant status.

In conclusion, our study has demonstrated that GSH has no effect on the cytotoxicity of CDDP to tumor cells and is able to attenuate the CDDP-induced nephrotoxicity in mice. We also confirmed that when administered at various times, GSH does not reduce the antitumor effects of CDDP and so should be beneficial to patients undergoing CDDP chemotherapy. These observations have clear clinical implications in future studies of GSH as a protector against CDDP toxicity.

\section{Acknowledgements}

This study was supported by the Shandong Province Science and Technology Development Plan Project (policy guidance class) (no. 2011YD18046).

\section{References}

1. Schrier RW: Cancer therapy and renal injury. J Clin Invest 110: 743-745, 2002.

2. Servais H, Ortiz A, Devuyst O, Denamur S, Tulkens PM and Mingeot-Leclercq MP: Renal cell apoptosis induced by nephrotoxic drugs: cellular and molecular mechanisms and potential approaches to modulation. Apoptosis 13: 11-32, 2008.

3. Madias NE and Harrington JT: Platinum nephrotoxicity. Am J Med 65: 307-314, 1978.

4. Taguchi T, Nazneen A, Abid MR and Razzaque MS: Cisplatinassociated nephrotoxicity and pathological events. Contrib Nephrol 148: 107-121, 2005.

5. Go RS and Adjei AA: Review of the comparative pharmacology and clinical activity of cisplatin and carboplatin. J Clin Oncol 17: 409-422, 1999.

6. Daugaard G: Cisplatin nephrotoxicity: experimental and clinical studies. Dan Med Bull 37: 1-12, 1990.
7. Zunino F, Pratesi G, Micheloni A, Cavalletti E, Sala F and Tofanetti O: Protective effect of reduced glutathione against cisplatin-induced renal and systemic toxicity and its influence on the therapeutic activity of the antitumor drug. Chem Biol Interact 70: 89-101, 1989.

8. Ajith TA, Usha S and Nivitha V: Ascorbic acid and alpha-tocopherol protect anticancer drug cisplatin induced nephrotoxicity in mice: a comparative study. Clin Chim Acta 375: 82-86, 2007.

9. Jiang N, Lu L, Wang T, Zhang L, Xin W and Fu F: Reduced glutathione attenuates liver injury induced by methyl parathion in rats. Toxicol Mech Methods 20: 69-74, 2010.

10. Skehan P, Storeng R, Scudiero D, Monks A, McMahon J, Vistica D, Warren JT, Bokesch H, Kenney S and Boyd MR: New colorimetric cytotoxicity assay for anticancer-drug screening. J Natl Cancer Inst 82: 1107-1112, 1990.

11. Jariyawat S, Kigpituck P, Suksen K, Chuncharunee A, Chaovanalikit A and Piyachaturawat P: Protection against cisplatin-induced nephrotoxicity in mice by Curcuma comosa Roxb. ethanol extract. J Nat Med 63: 430-436, 2009.

12. Kuhad A, Pilkhwal S, Sharma S, Tirkey N and Chopra K: Effect of curcumin on inflammation and oxidative stress in cisplatin-induced experimental nephrotoxicity. J Agric Food Chem 55: 10150-10155, 2007.

13. Kawai Y, Taniuchi S, Okahara S, Nakamura M and Gemba M: Relationship between cisplatin or nedaplatin-induced nephrotoxicity and renal accumulation. Biol Pharm Bull 28: 1385-1388, 2005.

14. Dobyan DC, Levi J, Jacobs C, Kosek J and Weiner MW: Mechanism of cis-platinum nephrotoxicity: II. Morphologic observations. J Pharmacol Exp Ther 213: 551-556, 1980.

15. Ali BH and Al Moundhri MS: Agents ameliorating or augmenting the nephrotoxicity of cisplatin and other platinum compounds: a review of some recent research. Food Chem Toxicol 44: $1173-1183,2006$

16. Xu Y, Jiang N and Yu H: Effect of glutathione combined with cisplatin and oxaliplatin on the proliferation and apoptosis of lung carcinoma cell line. Toxicol Mech Methods 20: 487-492, 2010.

17. Baek SM, Kwon CH, Kim JH, Woo JS, Jung JS and Kim YK: Differential roles of hydrogen peroxide and hydroxyl radical in cisplatin-induced cell death in renal proximal tubular epithelial cells. J Lab Clin Med 142: 178-186, 2003.

18. Jordan P and Carmo-Fonseca M: Molecular mechanisms involved in cisplatin cytotoxicity. Cell Mol Life Sci 57: 1229-1235, 2000.

19. Vermeulen NP and Baldew GS: The role of lipid peroxidation in the nephrotoxicity of cisplatin. Biochem Pharmacol 44: 1193-1199, 1992. 